\title{
Effects of varying concentration of soybean oils on hemato-biochemical profile in mice
}

\author{
M Salahuddin, M Sarker, N Ahmad, MA Miah*
}

Department of Physiology, Bangladesh Agricultural University, Mymensingh-2202, Bangladesh

\begin{abstract}
Plant fat like soybean oil is believed to be less harmful to our body compared to animal fat. To know the effect of soybean oil on hemato-biochemical profile, a total of 20, 6 weeks old "Swiss Albino" mice were randomly divided into 4 equal groups $(n=5)$. Group A was considered as control fed with rat pellets and others were treated with $2 \%$ (group B), 4\% (group C) and $8 \%$ (group D) soybean oil, respectively, in addition to pellets. At the end of 45 days, hemato-biochemical parameters were analyzed. The total erythrocyte count $(T E C)$ and hemoglobin $(\mathrm{Hb})$ content were increased significantly $(P<0.05)$ in group $C$ and $D$ compared to control group $A$ and the highest concentration was recorded in group $D$. The total serum cholesterol, triglycerides, HDL and uric acid were also increased significantly $(p<0.01)$ in group $C$ and D compared to control and highest value was recorded in group D. It is concluded that some haemato-biochemical parameters of blood in the mice are affected by soybean oil enriched diet.
\end{abstract}

Key words: , Hemato-biochemical profile, Mice, Soybean oil Bangladesh Animal Husbandry Association. All rights reserved.

Bang. J. Anim. Sci. 2013. 42 (2): 148-151

\section{I ntroduction}

As a high energy component of food, edible oils are important for calorie requirement. Protein and energy requirements of the animals are furnished by soybean meal and animal fat or oils respectively. However, food rich in fats and oils are also responsible for various cardiovascular and liver diseases. The presence of cholesterol, saturated fatty acids (Wood et al. 1996) and trans fatty acids (Anon 1997) in fats and oils increase the risk of coronary heart disease and atherosclerosis by increasing the blood cholesterol (Lichtenstein 1998). On the other hand, oils containing unsaturated fatty acids like soybean oil help to decrease the blood cholesterol as well as increase the level of LDL-cholesterol (Sugano et al. 1996; Sinha and Rahman 1995; Baron and Browner 1998).

The hematological and biochemical constituents of blood are relatively constant. Any physiological abnormalities or pathology is first reflected in the blood and body fluid. So, hemato-biochemistry permits the study of specific pathological alteration of certain blood constituents. The fatty acid profile of the diet are reflected in the fatty acid pattern of plasma lipoproteins. Increasing the linolenate in the diet will increase the linolenate level of lipoprotein types and thereby the polyunsaturated: saturated ratio. Cholesterol is an important metabolic precursor for biosynthesis of steroid hormones. It acts as a special transport agent for unsaturated fatty acids (Orten and Neuhaus 1970). Triglycerides are used for energy production; therefore twothird to three quarter of all the energy derived directly by the cells might be supplied with triglycerides (Guyton, 1971). The endogenous triglycerides which are synthesized by the liver and carries as bound to very low density lipoproteins (VLDL). VLDL is progressively removed from circulation by lipolysis which is enhanced by lipoprotein lipase enzyme attached to capillary endothelium of certain tissues (Laurence and Bennett 1992).The HDL cholesterol in blood acts as reverse transport mediators accepting cholesterol from peripheral cells like arterial walls and taking to the liver, thus it is protective against ischemic heart diseases (Laurence and Bennett 1992).

Information about hemato-biochemical parameters of blood of mice fed with different level of soybean oilis is scarce. Considering the above ideas, the study was conducted to know the effect of soybean oil on hematological parameters like total erythrocyte count (TEC) and hemoglobin $(\mathrm{Hb})$ concentration of mice and on lipid profiles as total serum cholesterol, triglycerides, high density lipoprotein (HDL) and low density lipoprotein (LDL) and on serum uric acid in mice. 


\section{Materials and Methods}

Six (6) weeks old 20 male Swiss Albino mice (Mus musculus) with an average body weight of 18-22g were obtained from ICDDR, B, Dhaka, Bangladesh. All mice were maintained in the animal care facilities according to animal care and use guidelines

After arrival, animals were allowed free access to a basal diet of standard rat pellet and water for 3 days to allow adaptation to new environment. The mice were randomly divided into 4 equal groups $(n=5)$ as A, B, C and D. Group A was considered as control fed on rat pellet ( 5 $\mathrm{g} /$ mouse/day) and fresh drinking water and others were fed on rat pellet enriched with soybean oil at the rate of $2 \%$ (group B), $4 \%$ (group C), 8\% (group D) for a period of 45 days.

On day 45, blood samples were collected by sacrificing the mice. The mice were kept fasting overnight. Then the mice were placed in an airtight container one by one containing choloroform presoaked cotton. They were checked for unconsciousness. The mice were taken out for blood collection. The abdominal cavity and thoracic cavity were opened and the blood was collected directly from the heart by a syringe. A portion of blood was taken in a test tube containing anticoagulant $13.8 \%$ sodium citrate solution). The remaining blood was used for the collection of serum.

About $2 \mathrm{ml}$ of blood was collected in the sterile glass test tube. The blood containing tubes were placed in slanting position at room temperature for 6 hours. The tubes were then incubated overnight in the refrigerator $\left(4^{\circ} \mathrm{C}\right)$. The serum samples were separated and centrifuged to get rid of unwanted blood cells where necessary. Serum samples were stored at $-20^{\circ} \mathrm{C}$ for biochemical analysis. The data were analyzed statistically by one way ANOVA followed by Duncan's multiple range test, where required.

\section{Results and Discussion}

Total erythrocyte count and hemoglobin concentration of blood of different groups of mice are presented in Table 1 . The TEC and $\mathrm{Hb}$ values were increased gradually in a dose depended manner and highest values were recorded in group D treated with $8 \%$ soybean oil which was statistically significant $(p<0.05)$ compared with values in group $A, B$ and $C$ groups. However, no significant differences was observed in TEC and $\mathrm{Hb}$ values among the groups of $\mathrm{A}, \mathrm{B}$ and $\mathrm{C}$.

The results were partially similar to Ahmed et al. (1994) who reported that $\mathrm{Hb}$ concentration affected by dietary treatment in Japanese quails and to that of Aletor et al. (1991) who reported that the values of TEC differed significantly among the different treated groups in broiler chickens.

Table 1. Effect of soybean oil on hematological parameters in mice.

\begin{tabular}{lllll}
\hline Hematological & \multicolumn{4}{c}{ Mean \pm SE } \\
\cline { 2 - 5 } parameters & Group-A & Group-B & Group-C & Group-D \\
\hline $\mathrm{TEC}\left(\mathrm{mill} / \mathrm{mm}^{3}\right)$ & $6.3^{\mathrm{a}} \pm 0.4$ & $6.1^{\mathrm{a}} \pm 0.12$ & $6.6^{\mathrm{a}} \pm 0.18$ & $8.4^{\mathrm{b}} \pm 0.16^{\star}$ \\
$\mathrm{Hb}(\mathrm{gm} \%)$ & $8.6^{\mathrm{a}} \pm 0.19$ & $8.0^{\mathrm{a} \pm 0.11}$ & $9.3^{\mathrm{a}} \pm 0.10$ & $11.4^{\mathrm{b}} \pm 0.17^{\star}$ \\
\hline
\end{tabular}

Means with different superscript in the same row differed significantly $(p<0.05)$

The effects of dietary supplementation of soybean oil on total cholesterol, triglycerides (TG), LDL, HDL and uric acid are shown in Figure 1. The total cholesterol values were increased in all treated groups at a dose dependent manner and highest value was recorded in group $D(p<0.01)$. The findings coincided with the findings of Fernandez et al. (1996) who reported that concentration of cholesterol concentration increased significantly in waster rats fed on diet enriched with $7 \%$ soybean oil but inconsistent with the findings of Kamei et al. (1996) who observed decreased plasma cholesterol in rats fed with hydrogenated soybean oil. A dose dependent increase in triglycerides concentration were observed in all treated groups. The TG concentration varied significantly $(p<0.01)$ among the groups. The highest triglycerides were recorded in group $D$ and lowest in group $A$. The result were similar to that of Fernandez et al. (1996) who found that triglycerides were significantly increased in Wistar male rat fed with soybean oil. The HDL differed significantly $(p<0.01)$ in the treated groups compared to control. This result is in agreement with the earlier report of Leplaix et al. (1996) who reported that dietary soybean oil induced an increase in the concentration of HDL. 

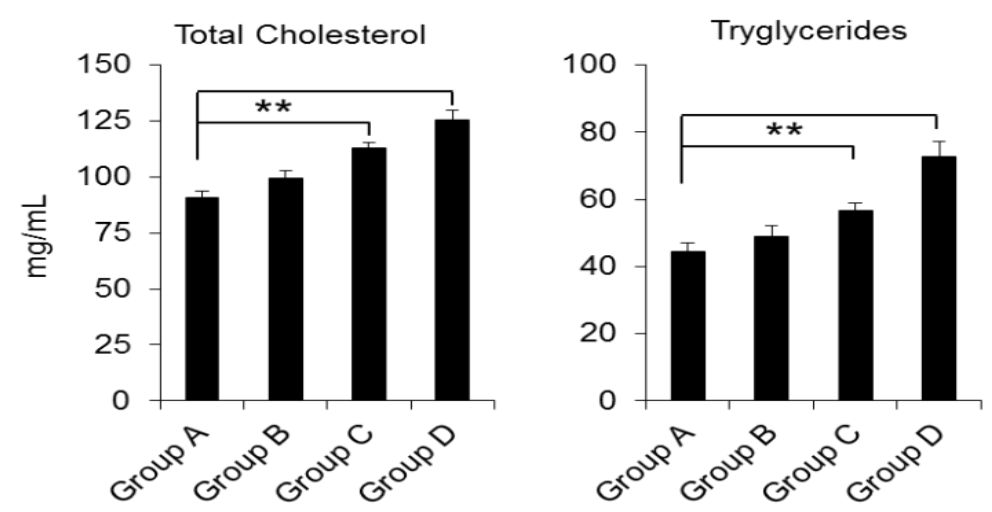

High density lipoprotein (HDL)
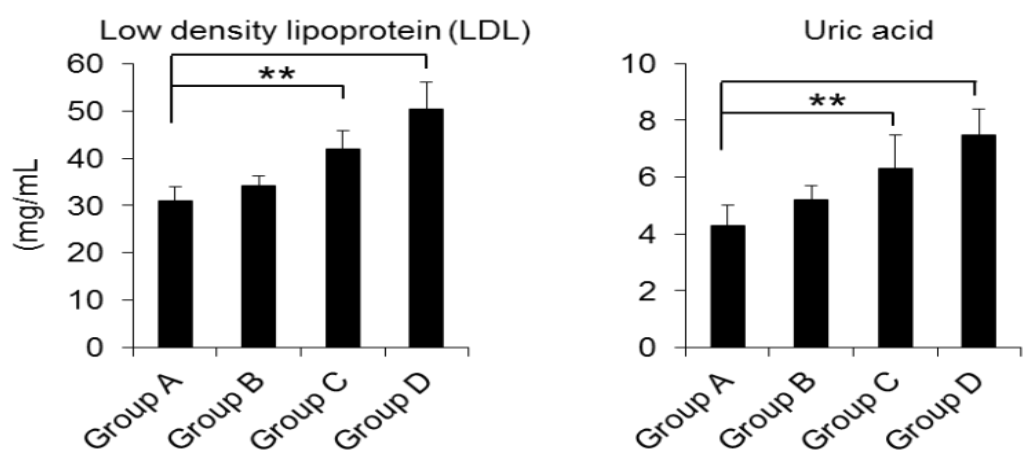

Figure 1. Effects of soybean oil on biochemical profile of blood of mice; ** $(P<0.01)$; group $A$, control; group B, $2 \%$ soybean oil; group C, $4 \%$ soybean oil; group D, $8 \%$ soybean oil

The serum uric acid concentration increased in all treated groups. The highest value was recorded in group $D$ and lowest in Group $A(p<0.01)$. The results were similar to that of Fernandez et al. (1996) who reported that uric acid concentration increased significantly in Wister rats fed on diet enriched with $7 \%$ soybean oil but inconsistent with the findings of Kamei et al. (1996) who observed decreased uric acid concentration in rats fed with hydrogenated soybean oil.

\section{Conclusion}

It is concluded that the values of TEC and $\mathrm{Hb}$ concentration and lipid profile are gradually increased with increased concentration of soybean oil added to the diet. However, more detailed studies are required to make final conclusion regarding the effect of soybean oil supplementation in mice.

\section{References}

Ahmed MK, Barque AR, Nawaz H, Siddique RH
(1994). Effect of varying energy and protein levels on the hematology of Japanese quails. Pakistan Veterinary Journal, 14: 200-202.

Aletor VA, Laseinde FAO, Ogunyemi O (1991). Equiprotein replacement of fishmeal with soybean meal in the diets for broiler chickens. Poultry Abstract, 17: 38.

Anonymous (1997). Trans in margarines are worse than butter. Nutrition briefs. MPOPC 2: 1 .

Baron BR, Browner WS (1998). Lipid abnormalities, In: Current Medical Diagnosis and Treatment. $37^{\text {th }}$ edition, Prentice Hall, New Jersey 1138- 1149.

Fernandez S, Gonzlez C, Diaz F, Fueyo AM, Gutierrez JM, Patterson AM (1996). Long term effects in two generations of enriched soybean oil and olive oil diets on some cardiovascular and biochemical parameters in male rats. International Journal for Vitamin and Nutrition Research, 66: 343399.

Guyton AC (1971). Text Book of Medical 
Salahuddin et al. (2013) Bang. J. Anim. Sci. 42 (2): 148- 151

physiology, $4^{\text {th }}$ Edition, WB Saunders Company. P. 801-802.

Kamei M, Ohagaki S, Kanbe T, Shimizu M, Morita S, Niiyal, Matsui YI, Otani S (1996). Highly hydrogenated dietary soybean oil modifies the responses to polychlorinated biphenyls in rats. Lipids, 31: 1151-1156.

Laurence DR, Bennett PN (1992). Clinical Pharmacology.7th edition. Produced by Longman Singapore Publisher (Ltd.). P. 453.

Leplaix CL, Bauchart D, Durand D, Lapland PM, Chapman MJ (1996). Plasma lipoproteins in pre-ruminant calves fed diets containing tallow or soybean oil with and without cholesterol. Journal of Dairy Science 79: 1267-1277.

Lichtenstein $\mathrm{AH}$ (1998). Trans fatty acid and blood lipid levels, $\operatorname{LP}(A)$, parameters of cholesterol metabolism, and hemostatic Factors. Journal of Nutritional Biochemistry 9: 244-248.

Orten J, Neuhaus M (1970). Biochemistry. Lipid metabolism, $8^{\text {th }}$ edition. The CV Mosby Company Saintlouis. P. 333

Sinha S, R Rahman (1995). Cholesterol lowering effect of hilsa fish oil in female rats. Bangladesh J ournal Biochemistry, 1: 9-15.

Sugano MT, Ishida T, Ide T (1996). Effects of various poly-unsaturated fatty acids on blood cholesterol and Eicosanoids in Rats. Agricultural and Biological chemistry, 50: 2335-2340.

Wood PDS, Shiods R, Kinsell K (1996). Dietary regulation of cholesterol metabolism. Lancet, 17: 604-607. 